\title{
Lost in transition at discharge
}

$\mathrm{T}$

he gap between theory and reality is often more of a rift than a flicker. Witness hospital discharge summaries. They are, in theory, the primary method of information exchange between an inpatient and outpatient care team about a patient's diagnostic findings, the hospital's management of the medical problem and arrangements for follow-up care.

Instead, in reality, there are often delays in completing discharge summaries, or they're treated as little more than a means of stamping "case closed" on a patient's file, leaving family physicians and outpatient specialists at loose ends, and such matters as patient safety and continuity of care essentially moot considerations.

The consequences? "If there's a gap in the plan of care, then the patient is exposed to adverse events whether it be an adverse drug event, or worsening of their symptoms, which may result in a hospital readmission," says Dr. Sunil Kripalani, a general internist at the Vanderbilt University Medical Center and researcher at the Center for Health Services Research at Vanderbilt's School of Medicine in Nashville, Tennessee.

Kripalani led a systematic review on communication and information transfer at hospital discharge which found that only $12 \%-34 \%$ of discharge summaries were available at the first postdischarge visit and just 51\%-77\% were available at four weeks (JAMA 2007, 297[8]:83141). In the 73 studies included for review, quality of care was affected in approximately $25 \%$ of follow-up visits, contributing, in turn, to considerable physician dissatisfaction.

As surprising was the "extent of gaps" in discharge summaries, Kripalani adds. They often lack critical information such as diagnostic test results, treatment or hospital course, discharge medications, patient or family counselling recommendations, and treatment follow-up plans.

"The implications are considerable," says Dr. Diana Toubassi, a family physician and director of the postgraduate education program at the Toronto Western Family Health Team in Ontario. She's convinced inadequate and incomplete discharge summaries

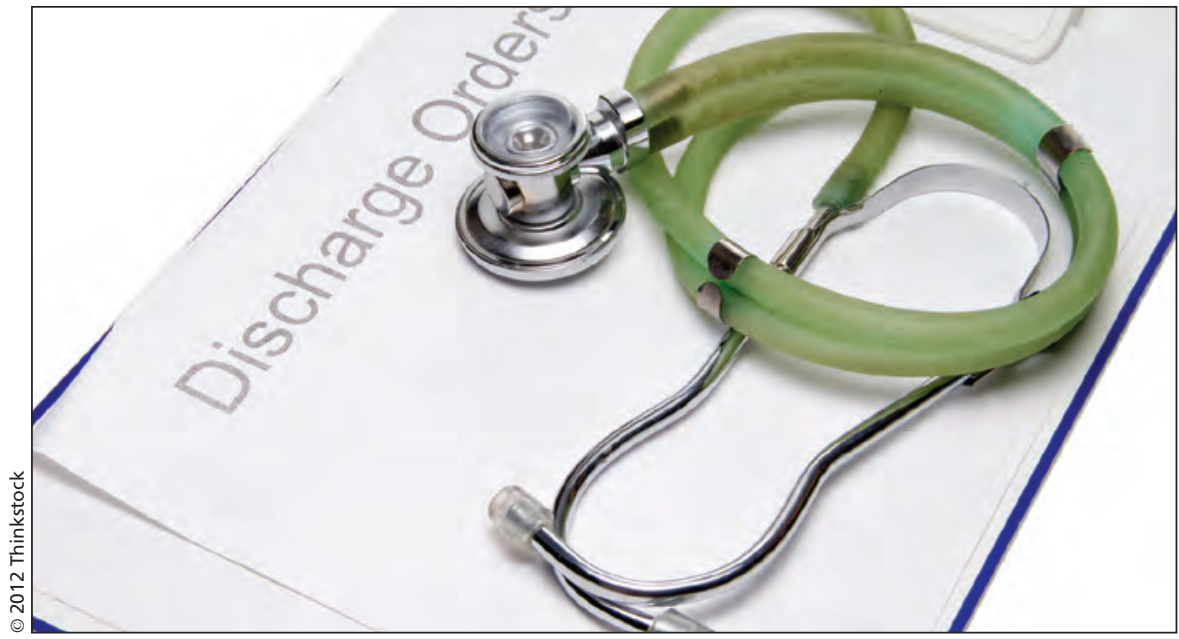

A systematic review found that discharge summaries often lack critical information.

have directly resulted in detrimental consequences for some patients. "I can think of very specific examples," she says, citing patients with congestive heart failure who were discharged with discontinuation of their diuretic therapy resulting in re-exacerbation of heart failure once they returned home.

By failing to provide adequate and comprehensive discharge summaries, hospitals are essentially abdicating their responsibility to ensure that a patient receives proper care, Toubassi says, adding that there are primarily two main areas in which safety is compromised. "Number one is with medication reconciliation, and understanding why changes were made. The second part is the follow-up plan, and making sure that investigations are followed up on and that referrals are made."

Such concerns are supported by a study conducted at the Ottawa Hospital in Ontario which found that $23 \%$ of patients discharged to the community from the general internal medicine service experienced an adverse event (CMAJ 2004;170[3]:345-9). The most common? Adverse drug events (72\%), followed by therapeutic errors (16\%) and nosocomial infections (11\%). Remarkably, $50 \%$ of the adverse events were preventable or ameliorable, and $17 \%$ resulted in readmission to hospital.

Small wonder that a recent survey of family physicians and family practice residents within the Toronto Western Family Health Team, conducted by Toubassi and colleague Dr. David Frost, indicated that most were dissatisfied with the quality of discharge summaries. The survey found that practitioners appreciate brief, concise, electronic and standardized summaries. Those should include a clear follow-up plan (with an itemized list of issues and tests pending at discharge); a medication reconciliation (with changes and reasons explicitly noted); and counselling for the patient and his family.

It's a common refrain. Studies in Norway, the Netherlands and the United States found discharge summaries to be inadequate, according to a paper, System Issues, Policies and Practices Affecting Physician Intraprofessionalism, commissioned by the Royal College of Physicians and Surgeons of Canada, the College of Family Physicians of Canada and the Canadian Medical Association (www.cfpc.ca/uploadedFiles /Directories/Committees_List/System _Issues_Policies_and_Practices_Affecting _Physician_Intraprofessionalism.pdf).

"Several interventions were found to improve communications" including computer-generated discharge summaries, "using patients as couriers," standardized formats for summaries and "structured" letters, the paper states.

It all points to the need to change the way hospitals approach discharge summaries, Toubassi says. "We need to look at them as tools of communication rather than academic or medico-legal exercises."

Kripalani concurs. Discharge summaries should be viewed as "transition 
management documents," he says. "What's really happening in many patient cases is not the end of an illness that needs to be summarized but rather a period of transition in their overall care, during which many changes have taken place and some management has been provided in the hospital and additional management will be provided subsequently in the outpatient setting."

There should also be a move toward a two-way flow of information, he adds. "In an ideal setting, there would be collaboration between the two physicians to review the current status of the patient in light of how they were before the hospitalization, and the primary care practitioner would have an opportunity to contribute to the plan of care before it's set and before [patients] leave the hospital, rather than being told of it afterwards."

The absence of such two-way communication is an invitation to "almost every type of error you can imagine," says Dr. Matthew Wynia, director of the Institute for Ethics and Center for Patient Safety at the American Medical Association and head of an expert panel struck by the association to review ambulatory patient safety (www.ama-assn.org /resources/doc/ethics/research-ambulatory -patient-safety.pdf).

"Much of what we're talking about here is a handoff of care responsibility from an inpatient to an outpatient team," says Wynia, a clinical assistant professor at the University of Chicago in Illinois. "I see this as very analogous to transferring a patient from the ICU [intensive care unit] to the floor [ward]. The idea that you would transfer a patient to the floor team without instructions would never happen because people recognize that it's handover of care responsibility."

Physicians more often have the notion of "this discrete thing called a hospitalization," where responsibility for care ends immediately upon discharge, Wynia says.

Kripalani suggests the start of a solution may lie in a name change, "something along the lines of a transition of care plan or transition of care summary. It could help shift peoples' thinking." Nathan Stall MD, Toronto, Ont.

CMAJ 2012. DOI:10.1503/cmaj.109-4318

\section{More news online}

Feds must step up and restrict generic oxycodone, Ontario says: It would be a "complete abdication of responsibility" for the federal government to allow generic oxycodone onto the market, Ontario's Health Minister charges (www.cmaj.ca/lookup/doi/10.1503/cmaj.109-4326). — Adam Miller, CMAJ

Senior suicide: An overlooked problem: (www.cmaj.ca/lookup/doi/10.1503 /cmaj.109-4287). — Michael Monette, CMAJ

Senior suicide: The tricky task of treatment: (www.cmaj.ca/lookup/doi /10.1503/cmaj.109-4288). — Michael Monette, CMAJ

Rural life hardly healthier: (www.cmaj.ca/lookup/doi/10.1503/cmaj.109 -4289). - Michael Monette, CMAJ

The boundaries of mental health first aid: (www.cmaj.ca/lookup/doi /10.1503/cmaj.109-4298). — Michael Monette, CMAJ

Making sense of the world's highest HIV rate: (www.cmaj.ca/lookup/doi /10.1503/cmaj.109-4315). — Barbara Sibbald, CMAJ

Healthier doctors, healthier patients: (www.cmaj.ca/lookup/doi/10.1503 /cmaj.109-4327). — Roger Collier, CMAJ

CMAJ 2012. DOI:10.1503/cmaj.109-4325 